\title{
Empreendedorismo feminino e agricultura: uma revisão sistemática da literatura
}

\author{
Female entrepreneurship and agriculture: a systematic review of the literature \\ Emprendimiento femenino y agricultura: una revisión sistemática de la literatura
}

Cinthia de Oliveira Rodrigues

ORCID: https://orcid.org/0000-0001-9555-3852

Universidade da Amazônia, Brasil

E-mail: cinthiairituia@gmail.com

Maria Lúcia Bahia Lopes

ORCID: https://orcid.org/0000-0002-3718-0434 Universidade da Amazônia, Brasil E-mail: malubahialopes7@gmail.com

Marcos Antônio Souza dos Santos ORCID: https://orcid.org/0000-0003-1028-1515

Universidade Federal Rural da Amazônia, Brasil E-mail: marcos.marituba@gmail.com

\begin{abstract}
Resumo
A pesquisa discuti o comportamento de estudos sobre o empreendedorismo feminino e agricultura. O objetivo consiste em analisar o perfil das publicações científicas relacionadas ao empreendedorismo feminino e agricultura no período de 2000 a 2021 com vistas a identificar oportunidades para futuras pesquisas por meio da revisão sistemática da literatura. Nesse recorte temporal foram analisadas 111 publicações, onde as abordagens das pesquisas estiveram muito alinhadas com as contribuições socioeconômicas das mulheres empreendedoras ao desenvolvimento mais sustentável. Os resultados evidenciaram que os estudos sobre empreendedorismo feminino abordam cinco categorias principais: a) Diversidade de gênero; b) Tecnologia e redes sociais; c) Empreendedorismo institucional; d) Análise de comportamento; e) Capacidade e estratégia empreendedora feminina. As principais pesquisas desenvolvidas foram de caráter qualitativo, se valendo principalmente da obtenção de dados primários para compreender o resultado em profundidade. Portanto, como sugestão de pesquisas futuras destaca-se a importância de realizar novas pesquisas voltadas para avaliar as metodologias de uso em políticas públicas voltadas ao tema e trazer ao cenário acadêmico o empreendedorismo feminino na agricultura tanto rural quanto urbana.
\end{abstract}

Palavras-chave: Empreendedorismo feminino; Mulher empreendedora; Agricultura.

\begin{abstract}
The research discusses the behavior of studies on female entrepreneurship and agriculture. The objective is to analyze the profile of scientific publications related to female entrepreneurship and agriculture in the period 2000 to 2021 with a view to identifying opportunities for future research through systematic literature review. In this time frame, 111 publications were analyzed, where the research approaches were closely aligned with the socioeconomic contributions of women entrepreneurs to more sustainable development. The results showed that studies on female entrepreneurship address five main categories: a) Gender diversity; b) Technology and social networks; c) Institutional entrepreneurship; d) Behavior analysis; e) Female entrepreneurial capacity and strategy. The main researches carried out were of a qualitative nature, making use mainly of obtaining primary data to understand the result in depth. Therefore, as a suggestion for future research, the importance of carrying out further research is highlighted, aimed at evaluating methodologies for use in public policies focused on the theme and bringing female entrepreneurship in both rural and urban agriculture to the academic scene.
\end{abstract}

Keywords: Female entrepreneurship; Entrepreneurial woman; Agriculture.

\section{Resumen}

La investigación discute el comportamiento de los estudios sobre emprendimiento femenino y agricultura. El objetivo es analizar el perfil de las publicaciones científicas relacionadas con el emprendimiento femenino y la agricultura en el período 2000-2021 con el fin de identificar oportunidades de investigación futura a través de una revisión sistemática de la literatura. En este lapso de tiempo, se analizaron 111 publicaciones, donde los enfoques de investigación estaban muy alineados con las contribuciones socioeconómicas de las mujeres emprendedoras para un desarrollo más sostenible. Los resultados mostraron que los estudios sobre emprendimiento femenino abordan cinco categorías principales: a) Diversidad de género; b) Tecnología y redes sociales; c) Emprendimiento institucional; d) Análisis de comportamiento; e) Capacidad y estrategia empresarial femenina. Las principales investigaciones desarrolladas fueron de carácter cualitativo, valiéndose principalmente de la obtención de datos primarios para comprender en profundidad el resultado. Por lo tanto, como sugerencia para futuras investigaciones, se destaca la importancia de realizar nuevas 
investigaciones encaminadas a evaluar las metodologías para su uso en políticas públicas enfocadas en el tema y llevar al escenario académico el emprendimiento femenino en la agricultura tanto rural como urbana.

Palabras clave: Emprendimiento femenino; Mujer emprendedora; Agricultura.

\section{Introdução}

O acesso das mulheres ao empreendedorismo e a redução das lacunas de gênero no mercado de trabalho são cruciais para o crescimento, a igualdade e a diminuição da pobreza na América Latina e no Caribe, destacou estudo de Comissão Econômica para a América Latina e o Caribe (CEPAL) e Organização Internacional do Trabalho (OIT) (2020). No entanto, ainda existem diferenças entre os países, tanto na taxa de crescimento econômico quanto nas condições de acesso ao trabalho feminino e um atraso significativo em comparação aos países desenvolvidos.

A participação da mulher no universo empreendedor nos países europeus, africanos e latino-americanos não são exatamente iguais. Contudo, nesses continentes há uma porcentagem significativa de mulheres em que, apesar da intenção do Estado em proporcionar um quadro para melhorar o acesso das mulheres ao mercado de trabalho, na prática esta mostra-se comprometida pela pressão social existente em torno do cumprimento dos papéis culturais e sociais da mulher. Desta forma o gênero é um dos principais obstáculos percepcionados na inserção profissional desta (Martinho, 2012; Lisboa, 2013; \& Cardoso, 2016;).

Atualmente o Brasil é o sétimo país com maior número de mulheres empreendedoras, segundo pesquisa publicada pelo Serviço Brasileiro de Apoio às Micro e Pequenas Empresas (SEBRAE) (2019), com dados levantados pelo Global Entrepreneurship Monitor (GEM), realizada com 49 nações. Totalizam mais de 24 milhões de brasileiras que desenvolvem negócios próprios, movendo a economia e gerando empregos.

Ao discutir o comportamento de estudos sobre o empreendedorismo feminino e agricultura, a pesquisa tem como objetivo analisar o perfil das publicações científicas relacionadas ao empreendedorismo feminino e agricultura no período de 2000 a 2021 com vistas a identificar oportunidades para futuras pesquisas por meio da revisão sistemática da literatura, metodologia que será descrito no item 3 do presente artigo.

\section{Empreendedorismo e Empreendedorismo Feminino Brasileiro}

O empreendedorismo é a capacidade de identificar os problemas e oportunidades, desenvolver soluções e investir recursos na criação de algo positivo para a sociedade; é a criação de um novo empreendimento, seja uma atividade autônoma e individual, uma nova empresa, a expansão de um empreendimento existente, um negócio, um projeto ou mesmo um movimento que gere mudanças reais e impacto no cotidiano das pessoas. A introdução de um novo bem, a criação de um método de produção ou comercialização e até a abertura de novos mercados, são algumas atividades comuns do empreendedorismo. Isso significa que a essência do empreendedorismo está na percepção e no aproveitamento das novas oportunidades no âmbito dos negócios (GEM, 2019; SEBRAE, 2019).

O campo de pesquisa sobre empreendedorismo é relativamente novo, no entanto, os pensamentos pioneiros sobre o conceito não o são. Segundo Landström et al., (2012), provavelmente a função é tão antiga como o intercâmbio e o comércio entre os indivíduos na sociedade, mas, no entanto, este conceito não era discutido. Somente a partir da evolução dos mercados econômicos, os cientistas se interessaram pelo fenômeno.

Essa discussão ocorreu após um grande período de estagnação aplicado pelo sistema feudal na economia europeia, onde o direito de propriedade era restrito e os produtos altamente taxados. Contudo, foi no período medieval que essas condições foram se modificando lentamente e o sistema de empreendedorismo evoluí-o com base nas classes dos comerciantes e na ascensão das cidades. Neste período, o termo empreendedor "foi usado para descrever tanto um participante quanto um administrador de grandes projetos de produção" (Hisrich et al., 2009, p. 28). 
Parte importante da literatura e da produção científica da área aponta que o indivíduo empreendedor deve ser visto como o elemento caracterizador e delimitador do conceito de empreendedorismo. Há, neste sentido, tentativas de se identificar as diferenças entre esses indivíduos e aqueles considerados como não empreendedores (Gartner, 1989; Filion, 1999; Williams; Nadin, 2013; \& Vale, 2014).

O empreendedor é definido como um indivíduo com habilidades e características de personalidade únicas, um estado fixo de existência definido a partir de traços psicológicos e de um comportamento particular (Gartner, 1989a, 2001b). Vale (2014) aponta que os empreendedores se situam em um mundo caracterizado por rápidas transformações e grande competição, e são vistos como personagens multifacetados. Gartner (2001) afirma ainda que o empreendedor seria um sujeito dotado de inovação, de espírito de iniciativa, que assume riscos em seu negócio, e que decide sobre o uso e coordenação de recursos escassos. Nassif, Andreassi e Simões (2011) defendem que empreendedores são dotados de competências em particular, influenciadas pela formação pessoal e profissional, bem como por suas motivações e habilidades, diferenciando-os assim de outros indivíduos.

No Brasil a atividade empreendedora liderada por mulheres vem se destacando a cada ano. Nesse grupo, a proporção de negócios por necessidade no Brasil é maior entre as mulheres , $44 \%$ de necessidade contra $32 \%$ no caso dos homens, do mesmo modo que as donas de negócio são (cada vez mais) "Chefes de domicílio" (45\%), GEM (2019).

Segundo Martinho (2012), o mundo vem assistindo, de forma crescente, que cada vez mais as mulheres caminham rumo ao protagonismo na economia em vários países do mundo, cargos que estas não ocupavam num passado recente. Pereira (2016) defende que o gênero detém um papel fundamental na participação de pessoas na atividade empreendedora, tendo o rápido crescimento do número de mulheres a ocupar cargos profissionais e de gestão alterando a disparidade de género na criação de novos negócios.

Historicamente as mulheres foram inseridas de forma marginalizadas na sociedade capitalista por meio da ocupação de postos de trabalhos desvalorizados tanto no tocante a remuneração quanto a natureza simples. Além da precarização laboral a que eram submetidas tiveram que diversas barreiras impostas pelos trabalhadores masculinos, onde as viam como concorrentes de seus postos de trabalho. Com a evolução do sistema capitalista até os dias atuais, apesar da crescente inserção feminina no mercado de trabalho, pudemos verificar a permanência e manutenção das desigualdades entre sexos em todas as esferas da sociedade (Salles Toro, 2018).

\section{Metodologia}

Conforme a classificação proposta por Loureiro (2018), esta é uma pesquisa de natureza aplicada, pois vale-se de conhecimentos já existentes, para produzir algo ou para solucionar um problema; exploratória e descritiva do ponto de vista de seus objetivos; possui uma abordagem qualitativa, pois os pesquisadores tendem a analisar os dados de forma holística e interpretativa; e na perspectiva dos procedimentos técnicos, enquadra-se em uma revisão sistemática de literatura.

As etapas para a construção deste estudo foram as seguintes: I) formular a pergunta de pesquisa; II) identificar as bases de dados e definir as estratégias de busca; III) selecionar e acessar a literatura; IV) avaliar a qualidade da literatura incluída na avaliação; e, V) analisar, sintetizar e divulgar os resultados (Cronin et al., 2008).

O cumprimento desse protocolo, neste trabalho, é explicitado a seguir:

I. Pergunta de pesquisa: qual o perfil das publicações científicas relacionadas ao empreendedorismo feminino e agricultura no período de 2000 a 2021 com vistas a identificar oportunidades para futuras pesquisas?

II. Bases de dados pesquisadas e as estratégias de busca: foram predefinidas quatro bases de dados científicos, sendo estas: Scopus, Scielo, Web of Science e Periódicos Capes.

Após a seleção dos bancos de dados, foi definido o período das publicações. O recorte temporal compreendeu aos anos 
de 2000 a 2021 em todos os seus meses de cobertura (janeiro a dezembro) com exceção para o ano de 2021, pois este levantamento foi realizado entre os meses de janeiro a maio deste mesmo ano. Em seguida, foram determinados os descritores a serem utilizados, que foram: "Female Entrepreneurship" or "Enterprising Woman" e "Entrepreneurial woman in agriculture".

Salienta-se que nas bases da Scopus, Scielo e Web of Science as buscas são permitidas somente no título, resumo e palavras-chave, sendo, portando, utilizado este filtro.

Para atender os objetivos da pesquisa, a busca na base Scopus adotou-se o filtro área Ciências sociais e idioma inglês; já na base Scielo, pesquisou-se somente os artigos em português e inglês na área de Ciências sociais aplicadas e subárea da agricultura, no Portal de Periódicos Capes, adotou-se o tópico Empreendedorismo, no período definido anteriormente

III. Critérios de inclusão e exclusão: para seleção dos artigos enquadrados na pergunta de pesquisa foi realizada a leitura do título, resumo, palavras-chave e conclusões de todos os artigos retornados em cada base, selecionando aqueles que abordavam o empreendedorismo feminino e excluídos os estudos repetidos e que não tratassem do tema em questão. A pesquisa respeitou a seguinte ordem: Scopus, Scielo, Web of Science, Portal de Periódicos Capes, sendo desconsiderados artigos repetidos em mais de uma base;

IV. Análise crítica dos estudos selecionados: procedeu-se a leitura integral dos artigos selecionados na etapa anterior a fim de extrair aspectos relevantes dos objetivos, metodologia, resultados e conclusões de cada estudo;

V. Síntese dos resultados: a exposição dos resultados teve como enfoque a descrição das principais características dos estudos como: a) categorias mais frequentes, b) abordagens mais utilizadas e c) janelas de oportunidades para futuras pesquisas.

\section{Resultados e Discussão}

O levantamento geral retornou um total de 868 artigos científicos dos quais foram catalogados 111 (Tabela 1) estudos que apresentaram temas diretamente relacionados ao empreendedorismo feminino e agricultura. As abordagens das pesquisas estiveram muito alinhadas com as contribuições socioeconômicas das mulheres empreendedoras, explorar as principais características e desafios enfrentados, assim como a importância das instituições públicas quanto ao desenvolvimento da atividade.

Tabela 1. Número de artigos retornados e selecionados para cada descritor e bases científicas no período de 2000 a 2021.

\begin{tabular}{cccccc}
\hline Descritor & Scopus & Scielo & $\begin{array}{c}\text { Web of } \\
\text { Science }\end{array}$ & $\begin{array}{c}\text { Periódicos } \\
\text { Capes. }\end{array}$ \\
\hline $\begin{array}{c}\text { "Female Entrepreneurship" } \\
\text { or"Enterprising Woman" }\end{array}$ & $\begin{array}{c}\text { Total de } \\
\text { retorno }\end{array}$ & 375 & 27 & 369 & 95 \\
\cline { 2 - 5 } & $\begin{array}{c}\text { Artigos } \\
\text { selecionados }\end{array}$ & 88 & 8 & 6 & 9 \\
\hline $\begin{array}{c}\text { Total de } \\
\text { retorno } \\
\text { agriculture" }\end{array}$ & 0 & 0 & 0 & 2 \\
& $\begin{array}{c}\text { Artigos } \\
\text { selecionados }\end{array}$ & 0 & 0 & 0 & 0 \\
\hline $\begin{array}{c}\text { Total de } \\
\text { retorno }\end{array}$ & 375 & 27 & 369 & 11 \\
\hline Total & $\begin{array}{c}\text { Artigos } \\
\text { selecionados }\end{array}$ & 88 & 8 & 6 & 9 \\
\hline
\end{tabular}

Fonte: Autores. 
A distribuição temporal dos estudos revela que o ano de 2020 foi onde a pesquisa sobre o empreendedorismo feminino mostrou-se mais evidente. Seguindo uma tendencia linear e crescente da evolução das pesquisas, os dados evidenciam o quanto as mulheres estão cada vez mais se posicionando junto a participação do mercado de trabalho. A Figura 1 apresenta a distribuição temporal das publicações de 2000 a 2021.

Figura 1. Evolução das publicações dos artigos selecionados (2000-2021).

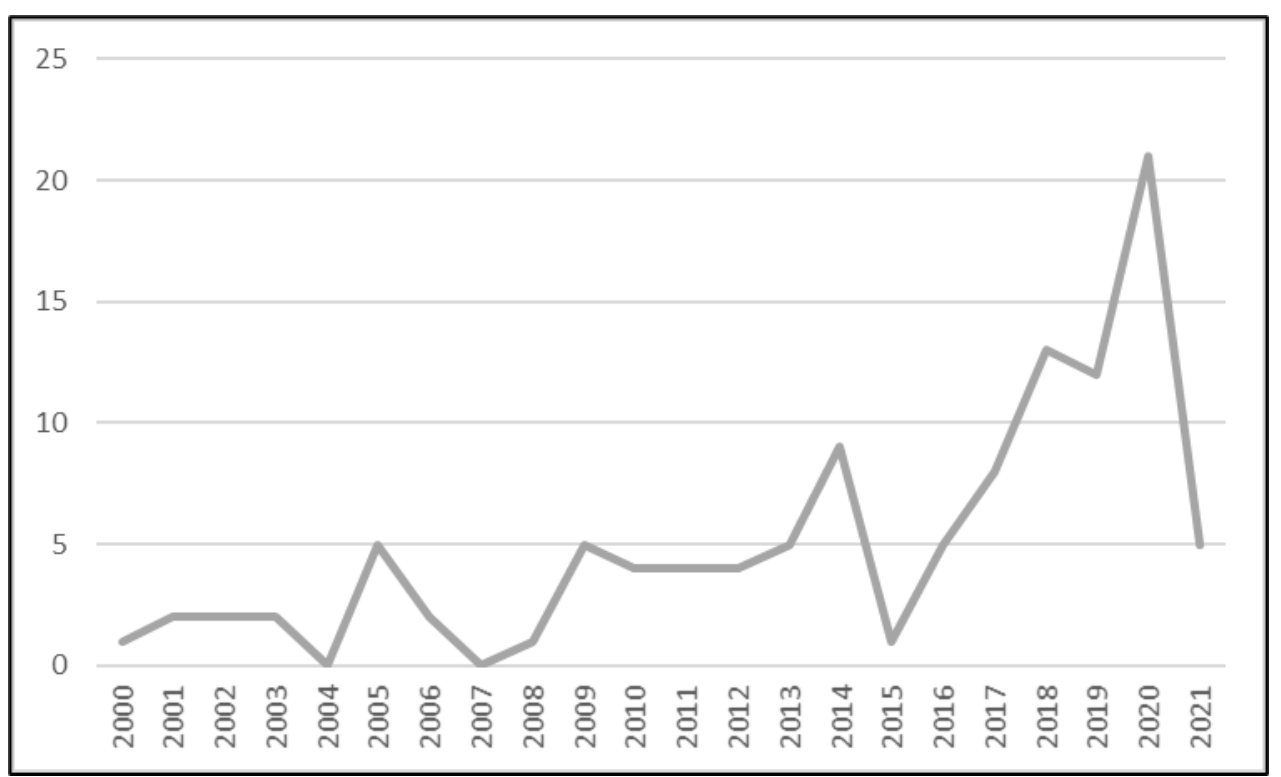

Fonte: Autores.

Os estudos selecionados foram classificados em cinco categorias: a) Diversidade de gênero; b) Tecnologia e redes sociais; c) Empreendedorismo institucional; d) Análise de comportamento; e) Capacidade e estratégia empreendedora feminina.

A categoria diversidade de gênero consiste em publicações que versam sobre objetivos relacionados a explorar as discriminações enfrentadas no empreendedorismo; a categoria Tecnologia e redes sociais consiste em estudos que enfatizam as tecnologias como aliadas no processo da dinâmica do empreendedorismo feminino; o empreendedorismo institucional consiste em estudos que tem como enfoque o papel das instituições no apoio a gestão e fomento no empreendedorismo feminino; a categoria análise de comportamento enfatiza estudos voltados para análise de caracteres específicos femininos no empreendedorismo e a categoria capacidade e estratégia empreendedora feminina consiste em apresentar os fatores que influenciam as habilidades empreendedoras em ambientes dominados por homens.

Segundo Medeiros (2011) o contexto social no qual as mulheres empreendedoras se inserem pode definir o seu carácter empreendedor, desde aspectos culturais a aspectos religiosos. Apesar do meio social e econômico exercer influência na forma das mulheres empreenderem, a empreendedora configura-se como uma mulher confiante, inovadora e criativa, capaz de obter independência econômica, gerar oportunidades de emprego e conjugar a sua vida profissional, familiar e social. A Tabela 2 apresenta as categorias e frequência dos artigos selecionados (2000-2021). 
Tabela 2. Categorias e frequência dos artigos selecionados (2000-2021).

\begin{tabular}{|c|c|c|}
\hline Categorias & Frequência & Referências \\
\hline $\begin{array}{l}\text { Diversidade } \\
\text { de gênero }\end{array}$ & $23 \%$ & $\begin{array}{l}\text { Salis, G; Flegl, M (2021); Ilie, C., Monfort, A., Fornes, G., Cardoza , G(2021); Kurtege Sefer } \\
\text {, B(2020); astida, M., Pinto, LH, Blanco, AO, Cancelo, M(2020); Stavytskyy, A., Kharlamova } \\
\text {, G., Giedraitis, VR, Cheberyako, O., Nikytenko, D(2020); Redd, TC, Wu, S.(2020); Adinolfi } \\
\text {, F., Capitanio , F., De Rosa, M., Vecchio, Y.(2020); Ennis , CA(2019); Eib , C., Siegert, } \\
\text { S.(2019); van Ewijk, AR, Belghiti-Mahut, S.(2019); Mersha, T., Sriram, V.(2019); Karimi , } \\
\text { H.(2018); Agyire-Tettey , F., Ackah , CG, Asuman , D.(2018); Güney-Frahm , I.(2018); } \\
\text { Kalafatoglu, T., Mendoza, X(2017); Perez-Quintana, A., Hormiga, E., Martori, JC, Madariaga } \\
\text {, R. (2017); Lo, MS(2016); Bahramitash, R., Esfahani , HS(2014); Patterson, N., Mavin , S., } \\
\text { Turner, J.(2012); Leung, A.(2012); Azam Roomi , M., Harrison, P.(2010); Smith, R.(2009); } \\
\text { Jamali, D.(2009); Yetim , N.(2008); Lewis, P.(2006); Levent , TB, Masurel , E., Nijkamp , } \\
\text { P.(2003); Browne, KE(2001); }\end{array}$ \\
\hline $\begin{array}{l}\text { Tecnologia e } \\
\text { redes sociais }\end{array}$ & $7 \%$ & $\begin{array}{l}\text { Steel, G(2021); Wang, Q., Keane, M(2020); Rodríguez-Díaz, R.(2021); Rodríguez- Vidales , } \\
\text { E., Moya-Fernández, PJ (2020); Teixeira, R, M; Andreassi, T(2020); Bomfim, L.C. S(2018); } \\
\text { Munkejord , MC(2017); Førde, A.(2013) }\end{array}$ \\
\hline $\begin{array}{l}\text { Empreendedorismo } \\
\text { institucional }\end{array}$ & $18 \%$ & $\begin{array}{l}\text { Li, Y, Wu, J, Zhang, D, Ling, L(2021); Kim, M., Abdullah, SC, Bich, NT, Boey , I(2020); } \\
\text { Savall, NV (2020); Seck, A., Araar, A., Camara, K., Diallo(2020); Hunt, CM, Fielden, S., } \\
\text { Woolnough, HM(2019); Yunis , MS, Hashim, H., Anderson, AR(2019); Kittilaksanawong, } \\
\text { W., Zhao, H.(2018); Dzombak, R., Mouakkad, S., Mehta, K.(2016); Valdivia, M.(2016); } \\
\text { Langevang, T., Gough, KV(2015); Yankson, PWK, Owusu, G., Osei, R.(2015); Lourenç, } \\
\text { F., Sappleton, N., (2014); Ghani, E., Kerr, WR, O'Connell, SD(2013); Hattab , H(2012); } \\
\text { Ekinsmyth , C. (2012); Sarri , KK(2011); Goby , VP, Erogul , MS(2011); Vale, } \\
\text { GMV(2010);Serafim, ACS; Teodósio, AS.(2011); Dhaliwal, S.(2010); }\end{array}$ \\
\hline \multirow[t]{4}{*}{$\begin{array}{l}\text { Análise } \\
\text { de } \\
\text { comportamento }\end{array}$} & $19 \%$ & $\begin{array}{l}\text { Ali, J., Shabir , S., Shaikh , A(2021); Kawai , N., Kazumi , T.(2020); Belghiti-Mahut, S., } \\
\text { Lafont, A.-L., Rodhain, A., Rodhain, F. (2020); Monteith, W., Camfield, L.(2019); Zapalska } \\
\text {, AM, Bugaj, MN, Rudd, D.(2019); ibes-Giner, G., Moya-Clemente, I.,(2019); Surangi, } \\
\text { H.(2018); Ferri, L., Ginesti, G., Spanò , R., Zampella, A(2018); Gohar, M., Basit, A., Abrar } \\
\text {, A.(2018); Pappas, MA, Drigas, AS, Papagerasimou, Y.(2018); abeen, F., Faisal, M.(2018); } \\
\text { Teixeira, R.M; Bomfim, L,C(2016); Morshed , A.(2014); Saeed , S., Malik, N.,(2014); } \\
\text { Strobino, MR; Teixeira, }\end{array}$ \\
\hline & & R M. (2014); Ferreira, Já.M; Nogueira, \\
\hline & & $\begin{array}{l}\text { E.S(2013); Menezes, RSS ; de Oliveira, JL(2013); Terrell , K(2010)., Troilo, M.(2010); Tynan } \\
\text {, M., Thomas, D.(2013) }\end{array}$ \\
\hline & & O'Gorman , B., Fuller-Love, N., Durand, M.(2009); \\
\hline \multirow[t]{2}{*}{$\begin{array}{c}\text { Capacidade/ } \\
\text { estratégia } \\
\text { empreendedora } \\
\text { feminina }\end{array}$} & $32 \%$ & $\begin{array}{l}\text { Dombrowski Risser, N. (2020); Al- Kwifi, OS, Tien Khoa, T., Ongsakul,V., Ahmed, ZU } \\
\text { (2020); Dawa, S., Namatovu , R., Mulira , F., Kyejjusa , S., Arinaitwe , M., Arinaitwe , } \\
\text { A.(2020); Echchabi, A., Omar, MMS, Ayedh, AM(2020); Disse, I., Enslin, C. (2020); Sousa } \\
\text { (2020); Akter, M., Rahman, M., Radicic , D.(2019); Alexandre, L., Kharabsheh , R.(2019); } \\
\text { Erogul, MS, Rod, M., Barragan, S.(2019); Zafarullah, H., Nawaz, F. (2019); Jung, K., Dalton, } \\
\text { B., Willis, J.(2018); Santos, G., Marques, CS, Ferreira, J(2018); Erogul, MS, Quagrainie, } \\
\text { FA(2018); Bokhari, AAH; Bokhari, AAH; Abalala, TS(2017); Bobrowska, S., Conrad, } \\
\text { H.(2017); Zapalska, A., Brozik, D.(2017); Kalemci Tuzun, I., Araz Takay , B.(2017); Lock, } \\
\text { R., Lawton Smith, H.(2016); Adom, K., Asare-Yeboa, IT(2016); Havik, PJ(2016); Fowler, } \\
\text { C.(2015); Paoloni , P., Dumay , J.(2014); Naguib, R., Jamali, D.(2014); Alperstedt, G.D ; } \\
\text { Ferreira, J.B ; Serafim, M.C(2014); Gomes, A. F; Santana, W.G.P; Araújo;U.P; Martins, } \\
\text { Caroline M. F(2014); Machado, H P V; Gazola, Se; A, Miguel E. M.(2013); ousuf Danish , A., } \\
\text { Lawton Smith, H.(2013); Poon , JPH, Thai, DT, Naybor , D.(2012); Minniti , M.(2010); } \\
\text { Sappleton, N.(2009); Almiralva FG; Weslei }\end{array}$ \\
\hline & & $\begin{array}{l}\text { GPS (2009); Yohn, SM(2006); Zapalska , AM, Bugaj, MN, Rudd , D.(2005); Machado, } \\
\text { H.V(2003); Bennett, R., Dann, S.(2000) }\end{array}$ \\
\hline
\end{tabular}

Fonte: Autores.

Os dados na tabela 2 revela que $32 \%$ das publicações estão relacionadas com o modo como a empreendedora feminina desenvolve a atividade, onde destacaram-se os três aspectos importantes como a motivação, a criatividade e a proatividade.

Para Dornelas (2003) o empreendedor é um indivíduo que sabe o que quer, deseja criar produtos e novos métodos, tem gosto no que faz e gere os seus conhecimentos de modo a encontrar diferentes formas de inovar, obtendo vantagem competitiva no mercado em que está inserido.

O empreendedorismo e o gênero são áreas temáticas que se podem unir de modo a demonstrar de que modo as relações de gênero se inserem no contexto empreendedor. As formas de empreender, de viver as experiências e de articular a vida no trabalho são distintas para homens e mulheres (Freire et al., 2011).

As publicações na categoria Diversidade de gênero, com $23 \%$, indicam que ser uma mulher empreendedora em uma 
sociedade patriarcal ainda limita as condições de sobrevivência e manutenção da atividade empreendedora devido à cultura e às normas sociais historicamente estabelecidas. De acordo com Schumpeter (1961), o sistema capitalista é um processo evolutivo, isto é, um sistema cuja dinâmica é baseada na capacidade contínua de os indivíduos se adaptarem ao ambiente econômico, sendo assim é fundamental encontrar a força motriz do sistema, não se iludindo com fatores que apenas superficialmente modificam suas estruturas.

Nessa perspectiva, destaca-se o caráter adaptativo do sistema capitalista, que possibilita os indivíduos mais habilidosos a reagir aos desafios do ambiente competitivo. Por meio da concorrência cria-se paradigmas econômicos, isto é, ocorre novas formas de interações econômicas entre os indivíduos ocasionando dessa forma, a destruição dos antigos.

Os estudos categorizados em análise de comportamento, com 19\%, indicam que a experiência de mulheres empreendedoras perpassa por barreiras e desafios onde inclui-se medo, frustração, estresse e raiva quando elas começam a gerenciar o negócio. No entanto, as mulheres também experimentaram sentimentos como coragem, paixão por aprender, empoderamento, destemor, ambição, determinação, persistência, e acreditar em si mesma. Para Dolabela (2010) o empreendedor faz as coisas acontecer, antecipando-se aos fatos e tem uma visão futura da organização. Segundo o autor o empreendedor é alguém que sonha e procura transformar o seu sonho em realidade.

Os estudos destacam que o empreendedorismo institucional, com 18\%, contribui com o desenvolvimento da análise, pois confirmam a complexa relação entre os componentes institucionais quanto a necessidade ao atendimento da demanda específica do empreendedorismo feminino. De acordo com Watson (2013), a ação empreendedora pode ser vista como uma categoria de criatividade contextualizada. De acordo com essa perspectiva, agir de forma empreendedora significa inovar, lidar com contextos sociais e econômicas e com situações que limitam e facilitam a definição de ações empreendedoras e de seus resultados.

$\mathrm{Na}$ sequência da análise, os estudos categorizados como tecnologias e redes sociais, 7\%, corroboram para a sustentabilidade no empreendedorismo feminino, pois as tecnologias disponíveis ajudam a conciliar trabalho e família. Uma inovação importante, como o uso de redes sociais, tende a induzir originais e diferentes inovações no mesmo setor, tornando criativo todo um processo de difusão e fomentando a manifestação do fenômeno do empreendedorismo (Baumol, 2010).

Quanto a tipificação das abordagens frequentes nas publicações selecionadas, a pesquisa revelou que a qualitativa corresponde a 59\%, estas versam sobre as desigualdades de gênero, privilegia grupos minoritários como mulheres indígenas, imigrantes e mães; a abordagem qualitativa-quantitativa representam $30 \%$ e prioriza estudos voltados a análise de externalidades que influenciam e motivam mulheres a empreender e a quantitativa representam $11 \%$, nessa abordagem a pesquisa evidenciou que os estudos objetivam estimar a eficiência e eficácia de instituições e redes de apoio no processo de criação e sustentabilidade de empresas lideradas por mulheres.

De forma geral, os estudos convergem sobre o investimento no empreendedorismo feminino ser essencial para os países ampliarem a formação de novos negócios concatenados com a sustentabilidade, uma vez que a mulher empreendedora identifica oportunidades, estuda habilidades criativas, assume e apresentam características de comportamento positivas tais como intensidade, afetividade, cortesia, humildade, valorização de ideias dadas por outrem e disponibilidade para aprender (Brito, 2008; Boaventura 2010).

\section{Considerações Finais}

Esta revisão sistemática permitiu catalogar 111 estudos sobre a temática em questão. A distribuição temporal das pesquisas exibiu uma tendência de crescimento ao longo dos anos, com picos de produção entre o ano de 2016 e 2020 .

Vale salientar que nos estudos selecionados relativos ao empreendedorismo feminino e agricultura, a literatura identificou dois trabalhos e que estes não atenderam aos objetivos da pesquisa. 
De modo geral, as pesquisas selecionadas tratam sobre empreendedorismo feminino e abordam cinco categorias principais: a) Diversidade de gênero; b) Tecnologia e redes sociais; c) Empreendedorismo institucional; d) Análise de comportamento; e) Capacidade e estratégia empreendedora feminina. As principais pesquisas desenvolvidas foram de caráter qualitativo, se valendo principalmente da obtenção de dados primários para compreender o resultado em profundidade.

A leitura integral dos estudos selecionados certificou que o empreendedorismo feminino ocupa espaço na literatura nacional e internacional devido a importância que exerce na construção do desenvolvimento mais sustentável. Contudo, sinalizou para a existência de uma série de desafios que ainda precisam ser superados, como políticas públicas adequadas voltadas a superar barreiras culturais que dificultam a inclusão e permanência da mulher no universo empreendedor; identidade de base criativa nos campos do empreendedorismo digital; incentivo de programas voltados para a promoção de cooperativas de mulheres; o uso de estudos qualitativos em profundidade por instituições relacionadas ao empreendedorismo de mulheres.

Portanto, como sugestão de trabalhos futuros destaca-se: a) investigar sobre o papel de redes de apoio no empreendedorismo digital feminino; b) identificar externalidades que dificultam o empreendedorismo feminino; c) analisar o empoderamento da mulher por meio do empreendedorismo; d) apresentar novos ramos do empreendedorismo que estão invisíveis no cenário acadêmico como o empreendedorismo feminino na agricultura tanto rural quanto urbana.

\section{Referências}

Baumol, W. J. (2010). The microtheory of innovative entrepreneurship. Princeton: Princeton University Press.

Boava, D., \& Macêdo, F. (2011). Empreendedorismo Explicitado à Maneira dos Filósofos. A Problemática Polissémica Intrínseca ao Empreendedorismo e das suas consequências para o estudo científico da atividade. V Encontro de Estudos em Estratégia. ANPAD -Associação Nacional de Pós-graduação e Pesquisa.

Boaventura, M. G. (2010). Gênero e empreendedorismo: mulheres empreendedoras no setor de moda em Belo Horizonte. Dissertação (Mestrado em administração), Faculdade Novos Horizontes, Belo Horizonte, MG, Brasil.

Dolabela, F. (2010). A corda e o sonho. Revista HSM Management, 80, 128-132.

Dornelas, J. (2003). Empreendedorismo corporativo: como ser empreendedor, inovar e se diferenciar em organizações estabelecidas. Rio de Janeiro: Elsevier.

Filion, L. J. (1999). Diferenças entre sistemas gerencias de empreendedores e operadores de pequenos negócios. Revista de Administração de Empresas, São Paulo. 39(4), 6-20.

Freire, D. A., Corrêa, R., \& Ribeiro, H. C. (2011). Género e empreendedorismo: um olhar sobre a pesquisa do G.E.M. - Global Enterpreneurship Monitor. Empreendedorismo e Inovação.

Gartner, W. B. (2001b). "Is there an elephant in entrepreneurship? Blind assumptions in theory development. Entrepreneurship Theory \& Practice, Boca Raton, 25(4), 27-39.

Gartner, W. B.(1989a). "Who is an Entrepreneur?” Is the wrong question. Entrepreneurship Theory \& Practice, Boca Raton. 13(4), 47-68.

GEM- Global Entrepreneurship Monitor. (2019). Empreendedorismo no Brasil: Relatório executivo. https://ibqp.org.br/PDF\%20GEM/Relat\%C3\%B3rio\%20Executivo\%20Empreendedorismo\%20no\%20Brasil\%202019.pdf.

Hisrich, R. D., Peters, M. P., \& Shepherd, D. A. (2009). Empreendedorismo. Tradução de Teresa Cristina Felix de Souza. Porto alegre: Bookman.

Landström, H., Harirchi, G., \& Aström, F. (2012). Entrepreneurship: Exploring the Knowledge base. Research Policy. 41(7). 1154-1181.

Loureiro, V.R. (2018). A pesquisa nas ciências sociais e no direito. Belém (PA), Cultural Brasil: UFPA/NAEA.

Martinho, S. (2012). Empreendedorismo Feminino: Motivações, características e obstáculos das mulheres empreendedoras em Portugal. Covilhã - Portugal, UBI. Dissertação (Mestrado em Ciências Humanas e Sociais). Universidade da Beira Interior.

Medeiros, J. (2011). Mulheres empreendedoras: Uma questão de gênero. Livro de Actas do Simpósio Género e Políticas Públicas, 1-14. Londrina.

Nassif, V. M. J., Andreassi, T., \& Simões, F. (2011). Competências empreendedoras: há diferenças entre empreendedores e intraempreendedores? Revista de Administração e Inovação, São Paulo. 8(3). 33-54.

Pereira, J. (2016). Empreendedorismo Feminino no ensino superior: Análise do Instituto Politécnico do Porto. Portugal. Dissertação (Mestrado em Gestão das Organizações) Instituto Superior Politécnico do Porto.

Salles T. M. A. R. (2018). A inserção da mulher no mercado de trabalho: emancipação ou precarização? Rio de Janeiro, RJ, PUC. Dissertação (Mestrado em Geografia e Meio Ambiente) Pontifícia Universidade Católica. 
Research, Society and Development, v. 11, n. 3, e42111326741, 2022

(CC BY 4.0) | ISSN 2525-3409 | DOI: http://dx.doi.org/10.33448/rsd-v11i3.26741

SEBRAE- Serviço Brasileiro de apoio às Micro e Pequenas Empresas. (2019). Mas afinal, o que é empreendedorismo?. https://blog.sebrae-sc.com.br/o-que-e empreendedorismo/\#: :text=Empreendedorismo\%20\%C3\%A9\%20a\%20capacidade\%20que,impacto\%20no\%20cotidiano\%20das $\% 20$ pessoas

Schumpeter, J. A. (1961). Capitalism, socialism and democracy New York: Harper and Brothers.

Vale, G. M. V., Corrêa, V. S., \& REIS, R. F. (2014). Motivações para o empreendedorismo: necessidade versus oportunidade? Revista de Administração Contemporânea, Rio de Janeiro. 18(3) 311-327.

Watson, T. J. (2013). Entrepreneurship in action: bringing together the individual, organizational and institutional dimensions of entrepreneurial action. Entrepreneurship \& Regional Development, Oxford. 25(5-6), 404-422.

Williams, C. C., \& Nadin, S. J. (2013). Beyond the entrepreneur as a heroic figurehead of capitalism: re-representing the lived practices of entrepreneurs. Entrepreneurship \& Regional Development, Oxford. 25(7-8), 552-568. 